\title{
Industrialização e Substituição de Importações no Brasil e na Argentina: Uma Análise Histórica Comparada
}

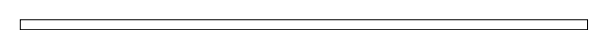

Lauro Mattei ${ }^{1}$

José Aldoril dos Santos Júnior ${ }^{2}$

\begin{abstract}
Resumo: Neste trabalho faz-se um resgate histórico do processo de formação industrial no Brasil e na Argentina, retornando aos primórdios da industrialização dos séculos XIX e XX, mas focalizando sua atenção no modelo de industrialização por substituição de importações. Neste caso, são destacadas as semelhanças e as diferenças entre os dois países e realçadas as características econômicas que guardam relações com a forma de estruturação desse modelo industrial e com as saídas distintas encontradas por ambos, quando o longo período de vigência das substituições de importações se esgotou. Como conclusão similar aos dois países aparece o fato de que ambos não conseguiram superar sua condição histórica de economias periféricas e dependentes de recursos externos, apesar de terem transformado seus sistemas econômicos.
\end{abstract}

Palavras-chave: industrialização; substituição de importações.

\section{Industrialisation and import substitution in Brazil and Argentina: a comparative historical analysis}

\begin{abstract}
The paper draws a historical review of industrialisation processes in Brazil and Argentina. It goes back to the beginning of the $19^{\text {th }}$ century, but focuses on the industrialisation through imports substitution model. The differences between the two countries are emphasized in terms of economics characteristics and industrial structures. The main conclusion is that neither countries managed to overcome their historical condition of peripherical economies in the world economic system, despite the transformation in the economics model of development in both countries.
\end{abstract}

Keywords: industrialization; imports substitution.

JEL: E60

\footnotetext{
1 Professor Doutor do PPGE/PUCRS. E-mail. vstulp@pucrs.br.

2 Professora Doutor do PPGE/PUCRS. E-mail. Izete.bagolin@pucrs.br
} 
MATTEI, L. \& SANTOS JÚNIOR, J. Industrialização e Substituição de Importações no Brasil...

\section{Introdução}

No início do século XX a principal característica das economias do Brasil e da Argentina era que ambas podiam ser consideradas como agroexportadoras, uma vez que praticamente toda a produção estava concentrada em poucos produtos de origem agrícola ou pecuária destinados ao mercado externo. No caso brasileiro a dinâmica econômica era dada pelo setor cafeeiro, enquanto que no caso argentino a concentração ocorria na produção pecuária e de cereais, principalmente trigo e milho oriundos da região do Pampa Úmido.

Enquanto as exportações de produtos primários representavam grande percentual da renda destes países, as importações eram a fonte de suprimento dos diversos tipos de bens manufaturados destinados à satisfação da demanda interna. Como grande parte da produção interna era voltado ao exterior, a capacidade para se fazer importações ficava condicionada pelo preço obtido pelas exportações e pela quantidade de produtos vendida aos outros países.

Porém, com as sucessivas crises no comércio exterior, sobretudo a partir de 1929, este modelo de desenvolvimento econômico entrou em colapso em ambos os países. A partir de então tem início nos dois países um processo de industrialização por substituição de importações, como resposta à queda da capacidade de importar provocada pela crise do comércio internacional.

Na Argentina, são identificadas cinco fases distintas no processo de formação industrial: os principais anos do período agroexportador, quando surgem várias indústrias produtoras de mercadorias ligadas ao setor dinâmico da economia; a chamada substituição de importações espontânea, compreendendo o período entre 1930 a 1945; o pós-guerra até meados da década 1960, ocorrendo a intensificação das substituições de importações, principalmente no período entre 1958 e 1960 quando a industrialização foi conduzida e planejada pelo Estado; um intenso surto de crescimento industrial entre 1963 e 1970; e a política de abertura comercial a partir de 1976, levando ao esgotamento desse modelo de desenvolvimento industrial.

No Brasil, o processo de substituição específico de importações também teve início com a crise de 1929, sendo que a sua vigência se prolongou até o final da década de 1970, quando ocorreram os choques do petróleo, o aumento da taxa de juros nos Estados Unidos e a crise do endividamento externo brasileiro. Verificam-se as seguintes fases neste processo: o nascimento da indústria em paralelo ao setor dinâmico agroexportador; o processo de substituição de importações, fundamentalmente dos bens de consumo não-duráveis; o crescimento industrial, 
prosperidade econômica e a consolidação da indústria leve de consumo no Brasil; o projeto industrial planejado e orientado pelo Estado através do Plano de Metas; e o período de crise e "milagre econômico", conjugando a formulação do II PND e a crise da dívida externa, colocando em xeque o modelo de substituição de importações.

Neste sentido, o trabalho faz uma análise histórica comparada dos processos de formação industrial nos casos brasileiro e argentino. A primeira seção procura identificar semelhanças e especificidades, além de ressaltar os principais aspectos deste processo em cada país, com o objetivo de entender as razões pelas quais o Brasil alcançou um grau maior de industrialização em relação à Argentina, apesar desse país ser considerado, durante o período agroexportador, a nação latino-americana mais rica. Além disso, serão apontadas as causas e conseqüências das contradições inerentes ao modelo de substituição de importações responsável pela formação industrial brasileira e argentina, sem deixar de caracterizar o papel que o Estado assumiu em relação aos projetos de industrialização nos dois países em apreço. A segunda seção apresenta as considerações finais do trabalho mostrando que, embora os dois países tenham obtido a condição de nações industrializadas na década de 1980, ocorreu uma série de contradições de ordem econômica e social que levaram ambos os países a uma crise sem precedentes na história.

\section{Formação industrial do Brasil e da argentina numa perspectiva histórica: do período agroexportador até a primeira guerra mundial ${ }^{3}$}

A divisão internacional do trabalho da época reservou, tanto para o Brasil como para a Argentina, o mercado para as exportações de produtos primários. A produção brasileira ficou dominada, basicamente, pelo setor cafeeiro que representava, em 1913, 62,3\% do total das exportações brasileiras. Já na Argentina a produção logrou um grau maior de diversificação, pois em 1913 o país recebia divisas por uma grande variedade de cereais, destacando-se o trigo, linhaça, centeio, cevada e milho, além dos produtos pecuários, como a carne congelada, lã e couro. Em contraste com o caso brasileiro, na Argentina o principal produto na pauta de exportações (milho) representava apenas $22,5 \%$ do total exportado. Destaca-se que as exportações Argentinas representavam quase $30 \%$ da renda obtida com exportações por toda América Latina.

As taxas anuais de crescimento das exportações entre 1850 e 1912 foram de 6,1\%, na Argentina, e de 3,7\%, no Brasil. Em 1913 a receita obtida com exportações foi de U\$ 510,3 milhões para a Argentina e de

3 Todos os dados deste item estão baseados em Bulmer-Thomas (1998). 
MATTEI, L. \& SANTOS JÚNIOR, J. Industrialização e Substituição de Importações no Brasil...

U\$ 315,7 milhões para as exportações brasileiras. Isto indica que a maior diversificação das exportações argentinas e o papel privilegiado que esta nação ocupou na divisão internacional do trabalho transformaram este país na nação mais rica da América Latina durante os anos orientados pela dinâmica agroexportadora.

Outra diferença importante deste período diz respeito ao destino das exportações: enquanto que os produtos brasileiros tinham como principal destino o mercado norte americano, representando $32,2 \%$ do total das exportações, a Grã-Bretanha era o destino principal dos produtos argentinos, representando $24,9 \%$ do total exportado pelo país.

Como a dinâmica produtiva estava voltada para o mercado externo, a oferta de bens internamente era satisfeita pelas importações, cuja capacidade para realizá-las ficava determinada pela quantidade de divisas obtidas pelo setor exportador. Também neste quesito verificou-se que o poder aquisitivo das exportações brasileiras esteve abaixo do verificado pela Argentina, tendo em vista que entre 1890 e 1912 o crescimento do poder aquisitivo das exportações argentinas foi de 5,4\%, enquanto que no Brasil foi de $3 \%$.

A industrialização da Europa e dos EUA produziu um excedente de bens manufaturados para o qual era necessário encontrar novos mercados. Argentina e Brasil, por possuírem um mercado interno considerável, ao mesmo tempo em que tinham bases industriais ainda incipientes e participavam de um sistema de comércio aberto, apareciam como mercados promissores para este tipo de bens. Em 1913 as importações brasileiras tiveram origem, principalmente, no Reino Unido $(24,5 \%)$ e nos EUA (15,7\%). Da mesma forma para a Argentina, o principal fornecedor de importações foi o Reino Unido (31\%), seguido pelos EUA, com 14,7\% do total.

O desempenho do setor exportador argentino fez com que o país obtivesse melhores resultados em relação aos obtidos pelo Brasil. A renda per capita na Argentina em 1913 era de 537 dólares, enquanto que no Brasil era de apenas 125 dólares. Portanto, verifica-se que o setor industrial na Argentina se desenvolveu acompanhando o setor exportador mais do que se verificou no Brasil. Segundo Rock (1988), apesar do volume de importações em relação ao PIB continuar elevado, entre 1895 e 1914 o número de fábricas duplicou e o investimento bruto na indústria aumentou cinco vezes. Neste período, os moinhos de farinha quadruplicaram, as refinarias de açúcar triplicaram e a produção de cerveja aumentou oito vezes. Durante a década de 1920 ocorreu um processo de diversificação industrial ainda maior, com destaque para as indústrias de bens leves de consumo, de produtos químicos, de eletricidade e de metalurgia. 
Em ambos os países a disposição dos recursos (força de trabalho e capital) para o desenvolvimento da indústria esteve ligada ao desenvolvimento do setor primário exportador. Quanto ao primeiro aspecto, tanto no Brasil como a Argentina, recorreu-se ao uso da força de trabalho migrante, sobretudo italiana. Para a Argentina a imigração esteve associada à necessidade de povoar o país. De fato, a imigração para a Argentina foi a mais notável, pois em 1890 mais da metade do aumento da força de trabalho ocorreu devido à imigração. Com isso, fortaleceu-se o mercado de trabalho local, propiciando um ganho real para o nível global de salários nos anos prévios à primeira guerra mundial. No Brasil a imigração européia esteve associada ao fim da escravidão e à necessidade de atender a demanda de trabalho do setor cafeeiro. Entretanto, este fluxo migratório não conseguiu organizar o mercado de trabalho e de salários, que se mantiveram baixos. Esta resistência em aumentar salários teve como efeito concentrar a renda obtida pelas exportações nas mãos de poucas pessoas ligadas à oligarquia cafeeira.

Quanto à disponibilidade de capital foi característico o intento de melhorar a eficiência do mercado de capitais, com a implantação de bancos modernos. O maior problema enfrentado pelos dois países foi o fato de que os financiamentos sempre priorizavam as atividades ligadas ao setor exportador, deixando pouco espaço para as atividades ligadas ao mercado interno. Deste modo, diante da dificuldade para mobilizar recursos nacionais para a acumulação de capital, os dois países adotaram a prática do endividamento externo. Antes da primeira guerra a dívida pública externa da Argentina era de 784 milhões de dólares, enquanto que a do Brasil era de 717 milhões de dólares, sendo a maior parte desta dívida resultado dos empréstimos ingleses (50,8\% do total dos empréstimos para o caso argentino e $83,4 \%$ para o caso brasileiro).

De um modo geral, a expansão do setor exportador ajudou a promover a urbanização dos dois países e contribuiu para o desenvolvimento de uma classe assalariada, ampliando o mercado para os produtos manufaturados. Esta demanda foi inicialmente satisfeita com importações, mas ao mesmo tempo criou oportunidades para que fossem transferidas as rendas do setor exportador para o setor manufatureiro nacional. Esta produção destinada ao mercado interno foi impulsionada, no Brasil, pelas dimensões de seu mercado, enquanto que para o caso argentino além deste fator, também se destacam o rápido crescimento das exportações e o produto per capita bem mais elevado.

Na década de 1920, as principais mercadorias industriais produzidas no Brasil estavam ligadas ao processamento de alimentos e bebidas, com 40,7\% do total da produção manufatureira. Já na Argentina o desempenho das indústrias processadoras de alimentos e de bebidas foi ainda maior, com 53,3\% do total produzido pela indústria. Assim, a 
MATTEI, L. \& SANTOS JÚNIOR, J. Industrialização e Substituição de Importações no Brasil...

Argentina, mesmo com uma população muito menor, apresentava um nível de valor agregado nas manufaturas muito maior comparativamente à produção brasileira, mesmo que sua produção total fosse inferior. Isto explica porque o produto industrial per capita do Brasil era de 16 dólares em 1920, enquanto que o da Argentina era de 84 dólares.

\section{Da Primeira Guerra Mundial até a crise de 1929}

Devido à Primeira Guerra Mundial, os países que não exportavam matérias-primas estratégicas tiveram suas condições comerciais deterioradas. O Brasil, dependente das exportações de café, não conseguiu sustentar as políticas de valorização do produto, levando a uma redução de $50 \%$ nos termos de trocas nos anos de guerra. A Argentina também teve suas exportações reduzidas e seus mercados externos restringidos, apesar do Reino Unido continuar dependendo da importação da carne da Argentina.

Quanto à posição adotada pelos EUA, estes assumiram o papel de exportadores de capitais e de parceiros comerciais preferenciais dos dois países. Mesmo assim, a Argentina conservou seu predomínio comercial com a Inglaterra e continuou sendo o maior mercado consumidor da América Latina, assim como o maior exportador da região. No entanto, o superávit que a Argentina tinha com o Reino Unido era compensado por um déficit comercial com os EUA. Já no Brasil ocorria o inverso, pois havia um déficit com a Inglaterra e um superávit comercial com os EUA.

Quanto ao desenvolvimento industrial, as dificuldades para se fazer importações provocaram mudanças em alguns setores na Argentina. Muitas indústrias, como as do ramo de metais, não conseguiram responder às restrições das importações e reduziram sua produção. Com isso, o índice de crescimento industrial argentino tornou-se inexpressivo e a produção total de 1913 não foi superada até meados da década de 1920.

Já a indústria brasileira mostrou visível contraste em relação à produção industrial da Argentina no período. Mesmo com a deterioração dos termos do comércio brasileiro, a demanda interna não diminuiu na mesma proporção. Isto aconteceu devido às políticas fiscal e monetária expansivas adotadas pelo governo, o que serviu de alento para as empresas aumentarem sua produção. Quanto ao papel do Estado, Suzigan (1982:41) afirma que "no período anterior à primeira guerra mundial praticamente nenhuma assistência foi concedida pelo governo brasileiro à indústria de transformação, com exceção da indústria de açúcar e, é claro, das ocasionais isenções de direitos sobre maquinaria importada 
e outras formas indiretas de apoio do governo, como por exemplo, o desenvolvimento do sistema de transportes, infra-estrutura, etc".

Durante a década de 1920 a Argentina recuperou seu crescimento industrial. A participação dos bens de consumo no total das importações caiu ao nível do período pré-guerra, devido ao aumento da produção de bens duráveis e não-duráveis em relação ao volume de importações dos mesmos. Além disso, se desenvolveram algumas indústrias intermediárias, como a de refinação de petróleo, química e metalurgia.

No Brasil, a valorização do café no começo da década de 1920 estabilizou a renda das exportações, permitindo que muitos recursos do setor cafeeiro, já em decadência, passassem a ser destinados ao setor industrial. A produção industrial aumentou durante os três primeiros anos da referida década, o mesmo acontecendo no período entre 1926 e 1928. Com isso, o saldo de todo decênio foi de crescimento da produção industrial da ordem de $55 \%$, a uma taxa anual média de $5 \%$. Entretanto, o fato mais contundente foi o grande volume de equipamentos industriais importados, criando-se grande capacidade industrial, além da modernização das plantas já existentes. Esta capacidade instalada foi fundamental para o processo de substituição de importações iniciado logo após a crise de 1929 .

Antes da crise de 1929, os bens industriais representavam 20\% do PIB total da Argentina, sendo que a produção manufatureira per capita era de 112 dólares (preços de 1970). Já a produção industrial brasileira representava $12,5 \%$ do PIB, enquanto que a produção manufatureira per capita era de apenas 20 dólares.

\section{Da substituição de importações não induzida até o processo de industrialização orientado pelo Estado}

\subsection{Fundamentos do modelo de industrializacão por substituição de importações}

Para Prebisch (1968), o centro desenvolvido não transferia seus aumentos de produtividade para a periferia atrasada. Além disso, se apropriava dos modestos incrementos de produtividade desta última, de modo que havia uma relação desigual entre os preços dos produtos manufaturados do centro e os preços dos produtos primários da periferia em favor dos primeiros, caracterizando-se como um intercâmbio desigual. O principal argumento de Prebish era de que, com o passar do tempo, o aumento da oferta de produtos primários faria com os preços destes produtos tivessem uma tendência de queda, enquanto que os 
preços dos produtos industriais apresentavam uma tendência de aumento.

É neste contexto que surge a idéia da substituição das importações de produtos manufaturados pela produção industrial nacional. O período de transição do modelo primário exportador para o modelo de industrialização por substituição de importações foi considerado por diversos estudiosos brasileiros como sendo a crise capitalista mundial de 1929, quando a capacidade de importação dos países produtores de bens primários se reduziu de forma acentuada devido à retração do comércio mundial. Este fato impulsionou o aumento da demanda pelos bens manufaturados produzidos internamente, elevando a expansão da oferta dos mesmos.

Tavares (1972:35) trabalha com a idéia de que as variáveis que determinam a capacidade de importar de um país são o quantum exportado por este país; o preço obtido pelas exportações; e o preço pago pelas importações realizadas. Outro conceito importante é o estrangulamento externo, que ocorre de forma absoluta quando a capacidade para importar se encontra estancada ou em queda e, de forma relativa, quando a capacidade para importar aumenta, porém a uma taxa inferior ao aumento do produto total da economia, ou seja, a demanda por importações cresce mais que a capacidade para importar.

Portanto, o início do processo de industrialização por substituição de importações no Brasil e na Argentina foi resultado de uma crise externa provocada pela deteriorização dos termos de trocas e pela queda na capacidade de importação verificada em ambos os países, sendo que a principal dificuldade para o avanço deste processo residiu no fato de que, ao mesmo tempo em que as importações foram substituídas por produção nacional, foram sendo criadas novas necessidades de importações qualitativamente distintas, obrigando a realização de novas rodadas de substituição.

Barros de Castro (1985) afirma que as substituições de importações na América Latina aconteceram através da implantação de atividades produtoras de bens de consumo duráveis. Foi um processo de diversificação do aparelho produtivo nacional situado predominantemente nos últimos estágios de produção. A substituição se referia, a rigor, a uma parcela maior ou menor do valor correspondente ao bem final. Neste caso, depois de realizada a substituição, a produção internalizada requeria a aquisição no exterior de determinadas peças, matérias-primas e componentes. 
MATTEI, L. \& SANTOS JÚNIOR, J. Industrialização e Substituição de Importações no Brasil...

\subsection{A expansão industrial via substituição de importações}

Tanto para a Argentina como para o Brasil a quantidade exportada e o preço recebido pelas exportações diminuíram como conseqüência da depressão mundial de 1929. Para se adaptar a estas circunstâncias e visando eliminar os desequilíbrios provocados pela crise externa, os governos desses países adotaram políticas de contenção das importações, sobretudo de controle do câmbio e de elevação das tarifas alfandegárias. Deste modo, as importações ficaram mais caras e as substituições de importações foram incentivadas. Além disso, serviu também como incentivo o fato de que as duas nações já possuíam uma considerável estrutura industrial e um mercado interno em expansão.

No Brasil, o crescimento industrial alcançado nos primeiros anos do Modelo de Substituição de Importações pela política de compra e queima dos estoques pelo governo, resultando na manutenção da renda dos cafeicultores e, por conseguinte, do nível de demanda interna, o que acabou estimulando o uso da capacidade ociosa das indústrias e deu início a substituição de importações de bens leves de consumo manufaturados (Furtado 1997).

Na Argentina o desenvolvimento do setor industrial também foi influenciado pelo tratado bilateral estabelecido entre a Argentina e a Inglaterra, chamado de Roca Ruciman. Este tratado dava aos produtos ingleses um preço mais baixo no mercado de importações argentino em relação ao oferecido por outros países que não estavam beneficiados pelo tratado, uma vez que a moeda inglesa ficava substancialmente mais barata na troca por pesos argentinos. Isto fez com que as importações estadunidenses, quando não proibidas, ficassem 20\% mais caras em relação às inglesas (Villanueva 1972).

Segundo este autor, a existência dessas barreiras serviu como incentivo para que as empresas dos EUA realizassem investimentos diretos em território argentino. Deste modo, a estratégia do governo argentino ao assinar o referido tratado com a Inglaterra teve uma intenção: por um lado, garantiu para o setor agropecuário do país o mercado inglês e, por outro, incentivou a diversificação industrial, tecnológica e organizacional, através da atração do capital norte-americano.

Segundo Katz \& Kosakoff (1989), o setor industrial, que em 1929 representava 18\% PIB argentino, passou para um patamar de 21\% em 1939. As indústrias que mais se desenvolveram no período foram as refinarias de petróleo, os artigos de borracha, os produtos químicos e farmacêuticos e, em menor escala, os produtos têxteis. Data desta época o surgimento de setores ligados à indústria metal-mecânica, de eletrodomésticos, de máquinas agrícolas e de ferramentas simples. 
Durante a década de 1930 a Argentina seguiu sendo a nação mais industrializada da América Latina, tanto pela participação das manufaturas em proporção ao PIB (22,7\%), como pela produção industrial per capita (122 dólares a preços de 1970). A produção manufatureira no Brasil subiu para $14,5 \%$ do PIB, enquanto que em termos per capita a produção industrial foi de 24 dólares. Porém, o dado mais significativo para demonstrar a evolução da indústria brasileira neste primeiro período de industrialização por substituição de importações foi a taxa anual de crescimento da produção industrial que, entre 1932 e 1939, foi de 7,6\%, patamar semelhante ao alcançado pela Argentina, 7,3\% (Bulmer-Thomas 1998).

Nos dois países, a maior importância dada ao setor industrial, acompanhada de intensa urbanização, elevou a demanda para os setores de infra-estrutura, como energia elétrica, transportes, serviços públicos e construção civil. Neste caso, destacou-se a construção de estradas, que tiveram um aumento particularmente expressivo para o caso argentino, ao absorver o excesso de trabalhadores disponibilizado pelo setor rural, enquanto que no Brasil a construção de estradas permitiu o escoamento da produção agrícola de regiões isoladas dos principais centros urbanos.

A industrialização realizada nos anos de 1930 teve como característica a mudança na composição da produção industrial nos dois países. Ainda que os processamentos de alimentos e tecidos continuassem sendo os ramos mais importantes, verificou-se a diversificação da indústria, ao mesmo tempo em que as relações inter-industriais se tornaram mais complexas. Dentre os novos ramos industriais destacam-se os produtos químicos e metálicos.

Durante a Segunda Guerra Mundial as dificuldades para se fazer importações em razão do conflito tiveram um duplo impacto para a produção de ambos os países. Por um lado, permitiu o avanço nas substituições de importações e, por outro, gerou um novo estrangulamento externo devido à impossibilidade para se fazer importações de bens de capital. Com isso, a produção industrial brasileira cresceu menos relativamente ao período anterior, sendo o crescimento de 5,3\% ao ano em média. Já na Argentina o setor industrial teve uma desaceleração ainda maior, uma vez que a taxa média anual de crescimento foi somente de $3,6 \%$ (Bulmer-Thomas 1998:284).

Para a Argentina o que ficou de mais característico deste período foi o crescimento de suas exportações industriais, pois estas representaram cerca de $20 \%$ do total produzido pela indústria do país. Outro aspecto importante foi o surgimento de uma pequena indústria de bens de capital apoiada na ajuda técnica dos Estados Unidos. Em território 
argentino surgiram empresas que tinham como demanda final, não os consumidores individuais, mas sim os setores produtivos e o Estado. Os exemplos são as indústrias de cimento, refinarias de petróleo, plástico e maquinarias.

No caso brasileiro foi iniciada a construção da siderúrgica de Volta Redonda financiada, em parte, pelos Estados Unidos, além de terem sido criadas outras indústrias ligadas ao setor de insumos industriais, como a Companhia Vale do Rio Doce e a Companhia Nacional de Álcalis, todas sob o controle estatal.

Do final da segunda guerra até 1955 o setor industrial brasileiro continuou se desenvolvendo a passos largos, tornando-se definitivamente o setor mais dinâmico da economia. Para tanto, foi de fundamental importância a política cambial adotada pelo governo que priorizou as importações de máquinas, equipamentos e matérias-primas para a indústria. Deste modo, o crescimento médio anual da produção industrial entre 1946 e 1955 foi de 8,5\% (Bresser Pereira 1985).

Na Argentina o governo peronista assumiu uma postura nacionalista e industrializante, restringindo ainda mais as importações que pudessem competir com as indústrias nacionais e concedendo créditos subsidiados à indústria local. Além disso, o Instituto Argentino para la Promoción Del Intercambio (IAPI), monopolizou a comercialização agrícola e transferiu a renda obtida para o setor industrial. Isto se traduziu no avanço do setor industrial, sendo que entre 1951 e 1958 a taxa média anual de crescimento industrial na Argentina foi de 5,3\% (Gerchunoff \& Llach 2003).

Desta maneira, comparando-se o grau alcançado de substituição de importações no início da década de 1950 com 1929, verifica-se que neste último ano $45 \%$ das manufaturas consumidas no território argentino eram importadas, proporção que caiu para $15 \%$ em 1950 (Gerchunoff \& Llach 2003). A diversificação do setor industrial ficou ao encargo dos setores de base, destacando-se a criação da siderúrgica SOMISA em 1946, o desenvolvimento de indústrias ligadas ao ramo químico entre outros (Katz \& Kosakoff 1989).

Em meados da década de 1950 havia terminado a etapa "fácil" de substituição de importações no Brasil e na Argentina. Porém, as indústrias destes países ainda dependiam das importações de máquinas e equipamentos, sendo que as divisas necessárias para se efetuar as importações ainda eram obtidas pelos ganhos do setor exportador, o que deixava as economias dos dois países vulneráveis às variações externas da demanda e dos preços dos produtos exportados. A partir de 1954, as condições externas voltaram a ser restritivas e a capacidade para importar se reduziu para os dois casos (Tavares 1972). Deste modo, para avançar no 
processo de industrialização e produzir internamente bens de capital e bens de consumos duráveis, foram formulados, em ambos os países, projetos desenvolvimentistas que visavam uma industrialização rápida e de forma integrada. Para cumprir com estes objetivos, foi essencial a participação do capital estrangeiro, através de investimentos diretos na produção e na instalação de empresas multinacionais e o papel do Estado atuando como planejador e organizador do processo.

No Brasil, o projeto desenvolvimentista foi chamado de Plano de Metas e teve vigência de 1956 até 1961. Os setores industriais consolidados após este plano foram os de bens de consumo duráveis, insumos intermediários, além das indústrias de base. Já a política econômica durante a vigência do plano foi expansiva e a taxa anual média de crescimento da produção industrial foi de $11 \%$ (Serra 1982). Porém este crescimento veio acompanhado por um conjunto de contradições. A taxa média anual de inflação entre 1955 e 1960 foi de $28 \%$, e entre 1960 e 1965, foi de 62\% (Bulmer-Tomas 1998), caracterizando-se o período do Plano de Metas como um período de crescimento com inflação. Além disso, verificaram-se altos índices de concentração regional e de renda, ficando a indústria dinâmica concentrada na região Sudeste do país e a renda concentrada nas mãos dos grandes capitalistas industriais, na classe média dos principais centros urbanos e na parcela mais qualificada dos assalariados empregada nas indústrias mais dinâmicas de origem multinacional e estatal.

Na Argentina, o projeto desenvolvimentista entre 1958 e 1962 seguiu os moldes do plano brasileiro. A proposta desenvolvimentista do Governo Frondizi pressupunha que o desenvolvimento econômico estava ligado ao desenvolvimento industrial. Apesar de o país ter realizado parte desse processo, a concentração da substituição de importações nas indústrias leves criou uma assimetria na estrutura industrial que comprometia as possibilidades de progresso do país.

Assim, para se alcançar uma economia industrial integrada foram definidas diversas prioridades: em primeiro lugar, o projeto desenvolvimentista argentino priorizou a produção de petróleo e de gás natural com o objetivo de economizar divisa estrangeira, isto porque em 1955 quase um quinto das importações do país eram constituídas pelos combustíveis. Em seguida, na lista de prioridades estava a siderurgia, cujo desenvolvimento dependia das explorações das reservas de carvão e de ferro. Neste sentido, havia uma vantagem relacionada ao término da construção da siderúrgica SOMISA. Ademais, o plano desenvolvimentista previa uma solução permanente para o problema da provisão de energia elétrica e o desenvolvimento das indústrias de cimento, papel, maquinarias e equipamentos industriais. Além disso, outras metas diziam respeito à construção de uma ampla rede de 
estradas, ao mesmo tempo em que se buscou estimular a produção nacional de automóveis e caminhões.

Este projeto aumentou a oferta interna de bens indústrias contemplando, basicamente, os mesmos setores industriais do plano brasileiro, sendo que um dos seus maiores êxitos foi ter alcançado a autonomia em relação às importações de petróleo. No entanto, ao contrário do Brasil, na Argentina a política econômica adotada durante a vigência do projeto desenvolvimentista foi restritiva e visou a estabilidade. A taxa média anual de crescimento industrial nestes anos foi de aproximadamente $3,8 \%$. Porém, considerando-se apenas os setores priorizados pelo projeto desenvolvimentista, o crescimento foi de $7,2 \%$ (Gerchunoff \& Llach 1975). Entre 1955/1960 a taxa média anual de inflação foi de $38 \%$ e de $27 \%$ entre 1960/1965, indicando que o crescimento industrial na Argentina foi relativamente menor que no Brasil durante a vigência de seus respectivos planos de desenvolvimento, porém acompanhado de maior estabilidade de preços.

Durante o decênio 1963/1973 a Argentina viveu o mais longo período de crescimento econômico desde os tempos do modelo primário-exportador. O Brasil, após o Plano de Metas, passou por um processo de estabilização econômica que, posteriormente, formaria as bases para uma fase de crescimento econômico de grande magnitude que duraria até meados da década de 1970. Nestes anos, foi similar para Brasil e Argentina, a tentativa de se incrementar as exportações industriais através da concessão de subsídios e de incentivos fiscais.

As reformas institucionais realizadas no Brasil foram orientadas pelas necessidades de um programa de estabilização capaz de servir como suporte ao crescimento futuro. Dentre as medidas adotadas, a mais significativa foi a redução dos salários reais assentada no poder autoritário do governo militar. Esta política de baixos salários favoreceu a acumulação de capital pela indústria, pois os registros indicam que a taxa média anual de crescimento industrial foi de 12,7\% entre 1968 e 1973. Além disso, segundo Lago (1989:233), "a política econômica do governo que tomou posse em 1967 assumiu uma estratégia geral sustentada, basicamente, na busca do crescimento econômico através do aumento dos investimentos em setores diversificados; na diminuição do papel do setor público e no estimulo a um maior crescimento do setor privado; nos incentivos à expansão do comércio exterior; e na elevada prioridade de aumento da oferta de emprego".

Na reforma tributária o governo brasileiro logrou aumentar sua arrecadação, permitindo um incremento mais racional das concessões de incentivos fiscais e subsídios aos setores considerados estratégicos. Já a reforma financeira criou os fundos de poupança compulsória 
(PIS, PASEP, FGTS) e ampliou o crédito para o consumo, recuperando parte da demanda reprimida dos anos de crise. Foi particularmente notável neste período a expansão do crédito (ao consumidor e à agricultura); a destinação de recursos para a construção civil; o elevado nível de dispêndio, por parte do governo, com investimentos em infra-estrutura; o endividamento das empresas estatais; e a manutenção dos mecanismos de correção monetária (Lago 1989).

A concentração de renda subjacente fez com que a classe média beneficiada pelo acesso fácil ao crédito garantisse a demanda por bens de consumo duráveis, permitindo à indústria automobilística uma produção em uma escala jamais vista na América Latina. Em relação às exportações industriais, houve um aumento considerável entre o início e o final da década de 1960, passando-se de uma receita de 28,4 milhões em 1960, para 420,5 milhões de dólares em 1970.

Na Argentina foi de grande importância para o crescimento econômico registrado durante a década de 1960 a capacidade ociosa herdada do projeto desenvolvimentista de Frondizi, que permitiu ao governo posterior adotar políticas monetárias e fiscais mais expansivas sem pressões sobre a capacidade produtiva. Assim, o setor industrial argentino estimulado pela capacidade instalada existente, pelo aumento na demanda e pela disponibilidade de divisas estrangeiras para se fazer importações, cresceu a taxas anuais médias de $7 \%$ entre 1964 e 1971. As exportações industriais também evoluíram nestes anos e as receitas das exportações, que eram de 44,3 milhões de dólares em 1960, aumentaram para 245,9 milhões em 1970 (Gerchunoff \& Llach 1975).

As indústrias ligadas aos setores dinâmicos foram as que mais cresceram, alcançando uma taxa média anual de 9,4\% entre 1964 e 1971, com destaque para a indústria química (10\%), a indústria metalúrgica (9,3\%), maquinaria não elétrica $(9,4 \%)$, maquinaria elétrica $(7,9 \%)$ e material de transporte (8,6\%) (Gerchunoff \& Llach 1975).

Cabe ressaltar que para se obter o crescimento foi fundamental o papel do capital estrangeiro, pois neste período se instalaram no país multinacionais ligadas ao setor automobilístico (Ford, Renault, Fiat, Peugeot e Citroen), além de outras corporações como Firestone, IBM, Duperial, Olivetti e Coca-Cola. Segundo Kats \& Kosakoff (1989:52) o setor industrial argentino recebeu mais 500 milhões de dólares em investimentos estrangeiros em meados da década de 1960, principalmente de origem norte americana. Neste contexto, a participação do setor automobilístico, que era de $2,5 \%$ do PIB em 1951, passou a ser 10,3\% em 1965 . 


\section{O fim do modelo de substituição de importações e a}

No Brasil, o fim do padrão de acumulação baseado na industrialização por substituição de importações orientada pelo Estado esteve diretamente relacionado ao crescente endividamento externo verificado desde o final da década de 1960, passando pelos anos do "milagre" econômico até a elevação da taxa de juros internacionais em 1979, quando a dívida externa brasileira atingiu patamares elevados.

Entre 1967 e 1973, a dívida externa líquida duplicou de tamanho, passando de 3.17 para 6.1 bilhões de dólares (Bresser Pereira 1985). Nestes anos, o endividamento esteve baseado no aumento da liquidez internacional proporcionado pela oferta de eurodólares. Os empréstimos efetuados tinham como finalidade financiar os déficits comerciais decorrentes do intenso volume das importações de matérias-primas e de máquinas necessárias à fabricação interna dos bens de consumo.

Ao final de 1973 os preços do petróleo se elevaram em quatro vezes, exigindo a restrição da política de déficits comerciais financiados pelo endividamento externo. No entanto, contrariando esta tendência, o governo militar formula uma estratégia de substituição de importações nos setores produtores de bens de capital e insumos básicos para a indústria. O II PND foi viabilizado através de sucessivos déficits comerciais: só em 1974 o montante deste déficit foi de 4.6 bilhões de dólares e a dívida externa bruta se elevou em quase 50\% (Bresser Pereira 1985).

Após a desativação parcial do II PND, em 1976, o endividamento externo chegou a um montante bruto de 32 bilhões de dólares, bem acima dos cerca de três bilhões registrados dez anos antes. Para agravar tal situação, em 1979 as taxas de juros internacionais foram elevadas em função da política monetária restritiva dos EUA. Como os contratos de empréstimos brasileiros foram negociados a taxas variáveis, os juros pagos pelo Brasil chegaram ao patamar de quatro bilhões de dólares. Em 1981 a dívida bruta chegou a 61.4 bilhões de dólares. Neste ano, os juros pagos aumentaram para 9.2 bilhões de dólares, equivalendo a 39\% das exportações brasileiras (Bresser Pereira 1985). A partir desta época, foram os pagamentos de juros e não mais os déficits comerciais os principais responsáveis pelo aumento da dívida.

Assim, o Brasil adentrou a década de 1980 imerso em uma crise de endividamento externo, que obrigou o governo a adotar políticas de ajuste nas contas externas e nos preços internos, orientando toda a produção nacional para o pagamento da dívida externa. Portanto, estes anos representaram o fim de um longo período de formação industrial que tirou o Brasil da condição de país exportador de produtos primários e o colocou como a nação mais industrializada da América Latina. 
Em 1973, a Argentina elegeu, pela terceira vez, Juan Perón como presidente do país. As principais medidas de seu governo foram no sentido de criar um pacto social visando um equilíbrio mutuamente aceito pelos trabalhadores e pelos capitalistas. Para atingir tal nível de equilíbrio, a política econômica peronista foi, ao mesmo tempo, distributiva e estabilizante. Deste modo, os salários e os preços foram congelados de acordo com uma lista oficial que reduzia os preços nominais de alguns produtos. Na prática, porém, nenhuma das partes envolvidas no pacto social ficou plenamente satisfeita. Por um lado, os sindicatos viam seu poder de negociação desaparecer e, por outro, os capitalistas tampouco estavam satisfeitos com um programa que iria reduzir a proporção do produto nacional recebida pelo capital.

Outro agravante para esta política de Perón foi o aumento dos preços internacionais do petróleo em 1973, com impactos diretos sobre os custos das empresas nacionais, fazendo com que estas passassem a exigir maior liberdade para transferir o aumento dos custos para os preços internos. Essa reivindicação dos empresários entrou em choque com a posição dos sindicatos, que defendiam a manutenção do nível dos salários reais, o que abalou, portanto, os alicerces do pacto social peronista. Este problema foi resolvido com a importação, a preços subsidiados pelo Estado, dos insumos então encarecidos. Esta medida reduziu as reservas em moeda estrangeira do governo e mostrou os limites e dificuldades para se levar adiante o pacto social.

Com a morte de Perón, desapareceu o último fator capaz de dar estabilidade e coordenação ao pacto vigente. O governo de Isabel Perón durou 20 meses e foi caracterizado por uma intensa instabilidade política. Já a política econômica foi orientada no sentido de redução do déficit fiscal e de atração de capital estrangeiro para equilibrar as contas externas. Porém, estas medidas não tiveram efeito, sendo que em 1975 a situação do balanço de pagamentos se deteriorou de tal maneira que o país foi obrigado a recorrer ao FMI. Além disso, as contas fiscais estavam totalmente descontroladas e os níveis de preços alcançaram cifras hiper-inflacionarias; 50\% em um só mês (Gerchunoff \& Llach 2003).

Diante deste quadro de descontrole econômico, a situação política se agravou, chegando-se a um novo golpe militar. Entre 1976 e 1981 o país foi governado pelo General Jorge Rafael Videla, cuja política econômica foi caracterizada por um plano de estabilidade econômica e austeridade fiscal. Já o setor industrial sofreu o impacto da política de liberalização comercial. A abertura comercial na Argentina buscou promover as exportações do país e abrir o mercado para as importações, ou seja, procurou-se eliminar todas as barreiras protecionistas e expor as empresas do país à concorrência internacional. 
Apesar da estratégia de abertura gradual, o quantum importado aumentou consideravelmente durante o governo Videla, gerando um crescente desequilíbrio comercial. A principal razão para isto foi a política cambial que minimizou os ganhos das exportações com a redução das tarifas e estimulou todos os tipos de importações. Esta política de valorização cambial provocou uma "avalanche" de importações e fez com que o setor industrial fosse o mais prejudicado pela abertura comercial, uma vez que a concorrência com os produtos importados tornou insustentável a situação de vários setores. O resultado foi que entre 1974 e 1980 a indústria teve sua participação no PIB reduzida em quatro pontos percentuais, sendo que para os setores têxtil e petroleiro a queda líquida foi da ordem de 15\% (Gerchunoff \& Llach 2003).

Assim, pode-se afirmar que a política de abertura comercial adotada na Argentina, além de selar o modelo de substituição de importações estimulou a desindustrialização, ao expor o complexo industrial do país à concorrência internacional. Ademais, no início dos anos de 1980 a Argentina padeceu das mesmas crises externas que afetaram o Brasil, isto é, déficits comerciais elevados e endividamento externo. Com isso, as obrigações externas aumentaram 31\% em relação ao ano anterior e o PIB teve uma queda de 9\%, entre 1981 e 1982 (Gerchunoff \& Llach 2003).

Várias são as razões que explicam o melhor desempenho do setor industrial brasileiro em relação ao argentino desde a etapa inicial do processo de industrialização por substituição de importações até a crise da dívida externa no final da década de 1970.

Primeiramente destaca-se o potencial do mercado interno brasileiro que, apesar de mais concentrado regionalmente e excludente em termos sociais, foi mais dinâmico em relação ao mercado interno da Argentina, o que permitiu maiores economias de escala para as principais indústrias situadas no país.

Além disso, segundo Tavares (1972), as condições externas mais favoráveis também foram fundamentais para o avanço da indústria no Brasil, que viu aumentar seus volumes de exportação e, por conseguinte, sua capacidade para importar, após a crise mundial de 1929 e a segunda guerra mundial.

Outro fator diz respeito à política salarial adotada pelo Brasil a partir de 1964, que comprimiu os salários reais e reduziu o poder dos sindicatos, permitindo uma intensa acumulação de capital por parte do setor industrial no período entre 1967 e 1973 . Ao contrário, a política salarial argentina valorizou os salários reais durante o primeiro governo de Perón (1946-1955) e durante o período de maior crescimento econômico (1963 a 1973). 
Finalmente, enquanto o Brasil realizou uma nova rodada de substituição de importações com o II PND, aumentando seu parque industrial até o início da década de 1980, a Argentina encerrou sua etapa de formação industrial com a política de abertura comercial de 1976, que levou à instalação de um processo de desindustrialização, acentuado fortemente na década de 1990.

Deve-se destacar, ainda, o papel que a questão política exerceu sobre o desenvolvimento industrial argentino, uma vez que os sucessivos golpes militares minaram as possibilidades de continuidade dos projetos industriais do país, culminando no processo de abertura comercial implementado pelo governo militar em meados da década de 1970. Merecem destaque os golpes militares impostos aos governos Frondizi, Ilia e Isabel Perón.

No Governo Frondizi percebe-se que, apesar do relativo sucesso do projeto desenvolvimentista, seu mandato foi conduzido num clima de ilegitimidade constante, pois as forças armadas argentinas se consideravam protetoras daquilo que entendiam ser o mais correto para o funcionamento da república. Com isso, impuseram claros limites às ações do governo civil. Deste modo, atitudes consideradas "progressistas" pelos militares em relação ao governo Frondizi levaram a sua deposição em 1962, gerando séria estabilidade institucional e com efeitos diretos sobre a condução do projeto desenvolvimentista argentino (Gerchunoff \& Llach 2003).

No Governo Ilia as mesmas formas de pressões foram impostas pelas forças armadas do país. No plano econômico, o governo iniciou um período de crescimento econômico e industrial, aproveitando-se das condições favoráveis do período anterior. No entanto, a negação do presidente para enviar tropas argentinas para Santo Domingo em apoio à intervenção Norte Americana, gerou uma imediata oposição dos militares, culminando com uma nova crise política e em mais um golpe militar no ano de 1966.

\section{Considerações finais}

Neste trabalho foi analisado o processo de formação industrial do Brasil e da Argentina, tendo como ponto de partida as primeiras manufaturas implantadas paralelamente ao modelo agro-exportador dos últimos anos do século XIX e primeiros anos do século XX. A partir do esgotamento deste modelo, verificou-se o início do processo de industrialização por substituição de importações, primeiramente de forma não induzida e, posteriormente, avançando para um estágio de planejamento orientado e comandado pelo Estado. Finalmente, fez-se uma comparação entre 
os referidos processos de formação industrial nos respectivos países, apontando como o modelo de industrialização por substituição de importações termina, tanto no Brasil como na Argentina, no final da década de 1970. Considerando a análise histórica feita neste trabalho, verifica-se que os processos de formação industrial do Brasil e da Argentina apresentaram um conjunto de semelhanças, tanto nas análises sobre a evolução da indústria nos dois países como em relação ao conjunto de contradições socioeconômicas geradas pelo modelo de desenvolvimento.

Considerando-se especificamente o período agroexportador, observase que em ambos os casos a divisão internacional do trabalho liderada pela Inglaterra relegou ao Brasil e à Argentina o papel de nações produtoras e exportadoras de produtos primários, dependentes da demanda externa por estes produtos e, ao mesmo tempo, dependentes da oferta externa de produtos manufaturados, fato que reprimiu o desenvolvimento da indústria no período nos dois países.

A crise econômica de 1929, todavia, colocou em xeque o modelo de desenvolvimento orientado para o mercado externo e introduziram, tanto no Brasil como na Argentina, o modelo de desenvolvimento orientado para o mercado interno e fundamentado na substituição de importações de produtos industriais.

Esta transição de modelos esteve amparada em distintos mecanismos. No caso do Brasil adotaram-se políticas de compra e queima dos estoques de café como forma de manter a renda do setor cafeeiro e impulsionar a demanda pelos produtos de origem industrial. A argentina adotou o tratado bilateral com a Inglaterra garantindo a manutenção da demanda inglesa pelos produtos primários do país e investimentos diretos dos Estados Unidos no setor industrial.

De maneira semelhante nos dois países, observa-se que o Estado foi fundamental na solidificação do setor industrial como setor dinâmico das duas economias, agindo principalmente no setor de infra-estrutura e concessão de crédito, além de executar os casos projetos desenvolvimentistas. Neste aspecto, apenas distinguem-se as políticas adotadas, pois enquanto no Brasil tal projeto foi implementado a partir de políticas econômicas expansivas e inflacionárias, na Argentina ocorreu através de políticas restritivas e com baixas taxas de inflação.

Nos dois países as crises externas dos preços do petróleo e dos juros norte-americanos, associadas a impossibilidade de novas substituições, foram os motivos que levaram ao fim do modelo de desenvolvimento orientado pelas substituições de importações. Porém, enquanto na Argentina a política de abertura comercial de 1976 iniciou um gradual processo de desindustrialização que se estendeu pelas décadas 
seguintes, no Brasil ocorreu uma nova rodada de substituições nos setores de infra-estrutura e de energia que garantiu um maior desenvolvimento do setor industrial brasileiro na década seguinte.

Assim, os dois países chegaram na década de 1980 na condição de nações industrializadas. No entanto, esta condição trouxe consigo um conjunto de contradições de ordem econômica e social, dentre as quais se destacam a inflação; o endividamento externo; a concentração de renda; a concentração industrial e regional; e a conseqüente manutenção de uma parcela da população excluída do progresso industrial.

Desta forma, foi similar ao caso brasileiro e argentino um intenso surto inflacionário durante boa parte do processo de formação industrial, que ocorreu devido ao financiamento dos gastos públicos através de emissão monetária; as deficiências no setor de infra-estrutura, que criaram gargalos produtivos e pressões nos preços; além da concentração industrial, que permitiu aos empresários manter suas margens de lucro, em função da produção estar oligopolizada.

No Brasil, os principais surtos ocorreram no final do Plano de Metas, quando o diagnóstico era de uma inflação de demanda e após o primeiro choque internacional dos preços do petróleo, em 1973, quando a inflação passou a ser considerada como uma inflação de custos. A inflação seria problema crônico para a economia brasileira por toda a década de 1980, chegando a uma taxa anual de 1.861,6\%, em 1989 (Bulmer-Thomas 1998).

$\mathrm{Na}$ Argentina, os maiores surtos inflacionários ocorreram durante os governos de Perón, que priorizaram políticas de salários elevados, além de consideráveis gastos públicos. Durante o último governo de Perón a inflação registrada foi de 50\% ao mês. Em relação à inflação de custos, da mesma forma que no caso brasileiro, a partir dos choques dos preços do petróleo, os níveis de preços se acentuaram e permaneceram altos por toda a década de 1980 . Em 1989, a inflação chegou a 4.923,6\% ao ano (Bulmer-Thomas 1998).

Outra contradição diz respeito ao fato de que a formação industrial do Brasil e da Argentina foi caracterizada por sua dependência em relação às importações ou financiamentos externos. Ou seja, nestes países a substituição de importações de bens de consumo apenas mudou a qualidade das importações realizadas, uma vez que houve um aumento da demanda por bens de capital e insumos básicos importados. Estas importações geraram déficits na balança comercial dos dois países que, para serem compensados, dependiam do desempenho do setor exportador ou da disponibilidade de crédito externo. 
Esta dependência se acentuou a partir da adoção dos respectivos projetos desenvolvimentistas no Brasil e na Argentina, pois o desenvolvimento industrial priorizou os setores de bens de consumo duráveis constituídos por empresas multinacionais. As indústrias desses setores tiveram como característica determinante demandar elevados volumes de importações. Além disso, as remessas de lucros das filiais para as sedes criaram constantes pressões sobre a necessidade de moeda estrangeira. Como os setores produtores de bens duráveis não exportavam seus produtos, as economias dos dois países ficaram ainda mais dependentes das condições favoráveis do comércio exterior para os setores primários, além da disponibilidade de crédito externo.

Já a concentração de renda e a concentração industrial ocorreram porque os setores dinâmicos do processo de industrialização, tanto no Brasil como na Argentina, eram setores intensivos em capital e demandantes de mão-de-obra qualificada. Deste modo, a concentração na indústria ocorreu devido às escalas de produção exigidas por estes setores para se obter uma produção lucrativa, enquanto que a concentração de renda foi resultado política salarial, aliada à formação de uma classe média que consumia os bens produzidos pelos setores dinâmicos, em detrimento de uma grande parcela da população excluída deste mercado de consumo.

Especificamente em relação ao caso brasileiro, a ação do governo militar, reduzindo os salários reais dos trabalhadores mediante restrições do poder dos sindicatos, intensificou o processo de concentração de renda. Assim, em 1959, o salário mínimo real no Brasil a preços de 1969 era de 331,50 Cruzeiros, diminuindo em 1964 para 279,55 Cruzeiros; e em 1970 ficou em 187,20 Cruzeiros (Bresser Pereira 1985).

$\mathrm{Na}$ Argentina, ao contrário, a concentração de renda foi atenuada pelo aumento dos salários reais durante o período de expansão que durou de 1963 até 1973. Isto ocorreu em função da recuperação por que passou o setor produtor de bens de consumo não duráveis que havia perdido espaço nos anos desenvolvimentistas de Frondizi (Gerchunoff \& Llach 1975). Além disso, os sindicatos sempre foram um instrumento de pressão sobre os salários desde os tempos do primeiro governo peronista, em 1946. Deste modo, os salários reais se valorizaram em $62 \%$ nos anos de Perón e em 40\%, entre 1963 e 1973 (Gerchunoff \& Llach 2003).

A concentração espacial ocorreu em associação à concentração de renda e à concentração industrial. No Brasil, o processo de industrialização ficou concentrado na região sudeste, enquanto que na Argentina praticamente todo parque industrial se formou na região de Buenos Aires. Desta forma, o desenvolvimento industrial do Brasil e da Argentina deixou uma parcela considerável da população, que não estava ligada 
diretamente aos setores produtores dinâmicos e aos grandes centros urbanos, excluída dos benefícios decorrentes do crescimento industrial, criando assim uma massa de desocupados ou de empregados mal remunerados, o que ajudou a agravar o quadro social nos dois países nas décadas seguintes.

Apesar dos graves problemas de ordem social, as contradições herdadas do modelo de industrialização por substituição de importações e que influenciaram as políticas econômicas nas duas décadas seguintes foram a inflação e a dívida externa. Nos dois casos as políticas procuraram estimular as exportações com o objetivo de efetuar o pagamento dos juros da dívida, além de reduzir os gastos públicos como medida para combater a inflação. O problema da dívida externa se acentuou ao longo da década de 1980 e o combate à inflação não logrou maiores êxitos depois que sucessivos planos de estabilização fracassaram nos dois países. Deste modo, os preços nos dois países chegaram, em 1989, a uma situação de hiperinflação.

Diante deste quadro e seguindo uma tendência internacional, os dois países adotaram políticas de liberalização comercial no começo da década de 1990. O objetivo desta política de abertura ao exterior foi buscar a estabilidade dos preços, através da maior oferta interna de produtos importados e da sobrevalorização cambial. Desta forma, essas medidas obrigaram os setores industriais do Brasil e da Argentina a uma rápida adaptação, em função da concorrência internacional.

O processo de abertura comercial no Brasil, apesar dos efeitos nocivos sobre o parque industrial, resultou na modernização de alguns setores que adquiriram um considerável nível de competitividade internacional, principalmente os ramos têxtil, calçados, metal-mecânico e agroindustrial. Já na Argentina, a abertura comercial dos anos de 1990 deu continuidade ao processo de desindustrialização verificado durante a abertura comercial realizada em 1976. Desta forma, o país tem hoje sua produção voltada, basicamente, à exportação de soja não processada, fato que se intensificou com a crise econômica vivida pelo país no inicio da década atual.

Portanto, se pode afirmar que, passados mais de vinte anos do fim do processo de industrialização por substituição de importações, o Brasil atingiu um grau maior de industrialização em relação à Argentina. No entanto, o país apresenta hoje um nível maior de concentração de renda e de desequilíbrios sociais em relação ao caso argentino. O que ficou de similar entre o processo de formação industrial do Brasil e da Argentina foi o fato de que estes países, apesar de terem formado seu parque industrial, não conseguiram superar suas condições de economias periféricas e dependentes do fluxo de recursos externos. 
MATTEI, L. \& SANTOS JÚNIOR, J. Industrialização e Substituição de Importações no Brasil...

\section{Referências}

BRESSER PEREIRA, L. (1985). Desenvolvimento e crise no Brasil 1930-1983. São Paulo: Brasiliense.

BULMER-THOMAS, V. (1998) [2003]. La historia económica de América latina desde la independência. Ciudad de México: Fondo de Cultura Económica.

CASTRO, A. \& SOUZA, F. (1985). A economia brasileira em marcha forçada. Rio de Janeiro: Paz e Terra.

DO LAGO, L. (1989). “A retomada do desenvolvimento e as distorções do milagre.” In: ABREU, M. P. (org.). A ordem do progresso: cem anos de política econômica republicana. Rio de Janeiro: Campus.

FURTADO, Celso (1997). Formação econômica do Brasil. São Paulo: Nacional.

GERCHUNOFF, P. \& LLACH, J. (1975). “Capitalismo industrial, desarrollo asociado y distribuición del ingreso entre los dos gobiernos peronistas: 1950-1972." Desarrollo Econômico 15 (57):3-54.

GERCHUNOFF, P. \& LLACH, J. (2003). El ciclo de la ilusión y del desencanto. Buenos Aires: Ariel.

KATZ, J. \& KOSACOFF, B. (1989). El proceso de industrialización en Argentina: evolución, retroceso y prospectiva. Buenos Aires: CEPAL.

PREBISCH, Raúl (1968). Dinâmica do desenvolvimento latino-americano. São Paulo: Fundo de Cultura.

ROCK, David (1988). Argentina, 1516-1987. Desde la colonización española hasta Raúl Alfonsín. Buenos Aires: Alianza.

SERRA, José (1982). "Ciclos e mudanças estruturais na economia brasileira do pós-guerra.” In BELLUZZO, L. \& COUTINHO, R. (orgs). Desenvolvimento capitalista do Brasil: ensaios sobre a crise. São Paulo: Brasiliense.

SUZIGAN, Wilson (1982). Indústria brasileira: origem e desenvolvimento. São Paulo: Nacional.

TAVARES, Maria (1972). Da substituição de importações ao capitalismo financeiro. Rio de Janeiro: Zahar.

VILLANUEVA, Javier (1972). "El origen de la industrialización argentina”. Desarrollo Económico 12(47):451-76.

Recebido em: 18 de fevereiro de 2008 Primeira resposta em: 22 de abril de 2008

Aceite em: 27 de junho de 2008 